\title{
The use of a mouthwash and a dentifrice containing antimicrobial phthalocyanine derivative on the reduction of clinical symptoms of COVID-19: A randomized triple-blinded clinical trial
}

Marcelo Lupion Poleti ( $\square$ marcelo.poleti@ifpr.edu.br)

Federal Institute of Paraná - IFPR https://orcid.org/0000-0003-1904-5762

Danielle Gregório

School of Dentistry, University of North Paraná - UNOPAR https://orcid.org/0000-0002-0098-624X

Alisson Gabriel Idelfonso Bistaffa

School of Dentistry, University of North Paraná - UNOPAR https://orcid.org/0000-0003-2070-1472

\section{Karen Barros Parron Fernandes}

University of North Paraná (UNOPAR)

\section{Fabiano Vieira Vilhena}

Trials - Oral Health \& Technologies https://orcid.org/0000-0003-3840-3633

\section{Paulo Sérgio da Silva Santos}

Bauru School of Dentistry of University of São Paulo https://orcid.org/0000-0002-0674-3759

\section{Andréa Name Colado Simão}

State University of Londrina https://orcid.org/0000-0002-2073-6782

\section{Marcell Alysson Batisti Lozovoy}

State University of Londrina https://orcid.org/0000-0002-4023-9548

\section{Berenice Tomoko Tatibana}

Federal Institute of Paraná https://orcid.org/0000-0002-8331-3066

Thais Maria Freire Fernandes

University of North Paraná (UNOPAR) https://orcid.org/0000-0002-4368-8568

\section{Research Article}

Keywords: COVID-19, Mouthwash, Dentifrices, Clinical symptoms

Posted Date: December 8th, 2021

DOI: https://doi.org/10.21203/rs.3.rs-1139111/v1

License: (c) (1) This work is licensed under a Creative Commons Attribution 4.0 International License. Read Full License 


\section{Abstract}

Purpose

This clinical trial aimed to evaluate the use of a mouthwash and a dentifrice containing antimicrobial phthalocyanine derivative (APD) on the reduction of clinical symptoms in COVID-19 patients.

\section{Methods}

This randomized triple-blinded clinical trial enrolled 500 patients aged 18 years or older submitted to COVID-19 test by nasopharyngeal swab RT-qPCR in a reference center for the diagnosis of COVID-19, had no clinical contraindications to perform mouthwash and gargle, and had access to cell phone with communication application. Patients were randomly assigned (1:1) to use a mouthwash, and a dentifrice both containing antimicrobial phthalocyanine derivative (APD Group) or Non-APD (Control Group). All participants were instructed to floss twice a day, toothbrushing during 2 minutes/three times a day, and for gargling/rising ( $5 \mathrm{ml})$ during 1 minute/three times a day for 7 days. An online questionnaire was sent to collect the clinical symptoms of COVID-19 in three times: T0 (baseline - before using the oral hygiene products); T3 (three days after); and T7 (seven days after). The investigators, patients, and outcomes assessor were blinded to group assignment. Mann-Whitney test, Chi-Square test, Exact Fisher test, and Cochran's test were used according to the nature of the variables studied, with the level of significance set at $\mathrm{P}<0.05$.

\section{Results}

No statistically significant difference was found in the prevalence of symptoms between the groups at baseline. A statistically significant reduction of clinical symptoms was found in the Control Group (fatigue, shortness of breath, hoarse voice, sore throat, nasal congestion, and chest pain) and in APD Group (cough, fatigue, shortness of breath, hyposmia/anosmia, dysgeusia, hoarse voice, sore throat, nasal congestion, chest pain, diarrhea and irritability/confusion) during the follow-up period. There were statistically significant differences with a higher symptoms' prevalence for the Control Group at T3 and T7. Dysgeusia, sore throat, irritability/confusion was less prevalent at the APD Group at T3, and shortness of breath, hyposmia/anosmia, dysgeusia, hoarse voice, sore throat, diarrhea, and irritability/confusion were more prevalent in the Control Group at T7.

\section{Conclusions}

Based on methodology, the results demonstrated that the regular use of mouthwash and dentifrice containing APD had a positive impact on the clinical symptoms reported by COVID-19 patients.

\section{Introduction}

Oral health care has been reported as one of the COVID-19 worries $^{1-5}$. Recent surveys showed that the global neglect of dental care has affected the population mainly due to the lack of self-care, which in a way directly impacts general health. ${ }^{1,5-9}$ Since the involvement of the mouth in the pathophysiology of COVID-19, oral hygiene has become more important in terms of preventing contamination and dissemination of the SARS-CoV-2. ${ }^{2-4}$

Antiseptic products are already used for oral health care. However, during the pandemic it was hypothesized that these products could be used as an adjuvant for COVID-19 combat. ${ }^{10-12}$ Recently, studies have shown some interesting clinical and laborator. ${ }^{10-15}$ On the other hand, the daily use of some oral hygiene virucidal products cause adverse effects such as thyroid problems, alteration in taste, staining of teeth, calculus formation, among others. ${ }^{16-18}$

In this pandemic context, some oral antimicrobial products have been investigated for the maintenance of oral hygiene and as a preventive measure against COVID-19, especially those containing chlorhexidine, hydrogen peroxide, povidone iodine 
and, more recently, an antimicrobial phthalocyanine derivative (APD). ${ }^{19,20}$ In one of these APD studies, the authors reported that COVID-19 hospitalized patients experienced faster recovery and hospital discharge without disease progression after using an adjuvant APD rinse protocol. ${ }^{21}$ The same protocol was used by non-hospitalized patients diagnosed with COVID-19 and were reported in two case series. ${ }^{22,23}$ In these studies the patients had a reduction in clinical symptoms such as sore throat, cough and mouth sores and became asymptomatic after a few days of use. In additional, a pilot study the authors showed reduction of viral load of SARS-CoV-2 after toothbrushing with a dentifrice containing APD ${ }^{14}$ and an in vitro study demonstrated SARS-CoV-2 inactivation with a mouthwash (90\%) and a dentifrice (99,99\%) both containing APD. ${ }^{19}$ However, as this is a new technology, there are no results from clinical trials with the APD in patients with COVID-19 during the early stage of the disease.

In the current study we tested the hypothesis that use of a mouthwash and a dentifrice containing APD would reduce the clinical symptoms of COVID-19 during the early stage of the disease.

\section{Patients And Methods}

\section{Trial design}

This was a clinical trial, randomized (1:1), triple-blind, parallel-group conducted in a reference center for the diagnosis of COVID-19. The study protocol was approved by the National Commission of Research Ethics, Brazil, on October 22, 2020 (\# 35530020.1.0000.8156), upon acquiescence of the Londrina Municipal Health Authority and was registered in the Brazilian Registry of Clinical Trials - REBEC (RBR-8x8g36). This study was performed according to the Consolidated Standards of Reporting Trials. ${ }^{24}$

\section{Participants}

Eligible participants were patient adults aged 18 or older submitted to COVID-19 test by nasopharyngeal swab RT-qPCR, had no clinical contraindications to perform mouthwash and gargle, and had access to cell phone with communication application (WhatsApp). Exclusion criteria were negative COVID-19 tests, who did not answer the clinical questionnaires, and did not use the oral products as recommended. Recruiting of participants in this study took place at a reference center for the diagnosis of COVID-19, in Londrina - Brazil, from November 6-19, 2020. Londrina has 580.000 habitants and had a 7-day moving average of 124 new COVID-19 cases when this study was performed.

Sample size calculation had been performed based on the APD group of a previous study with hospitalized patients ${ }^{21}$ with an alpha level of 0.5 and beta value of 0.2 to attain $80 \%$ test power, 40 patients were required for each group. However, considering that approximately $80 \%$ of the COVID-19 tests were negative at the referral center for this study, in October 2020 , 250 patients were needed for each arm.

\section{Randomization and blinding}

Randomization was performed by an external investigator (T.F.) with no clinical involvement in the trial, using a computer program (Excel 2007, Microsoft Windows, Microsoft, Chicago, IL, USA), and was stratified by group with a 1:1 allocation using random block sizes of 20. This investigator inserted the codes according to the randomization schedule in prepackaged kits with a toothbrush, a floss, a mouthwash, and a dentifrice with APD (APD group) or Non-APD (control group). These kits were identical in appearance, taste, smell, and method of use and the allocation sequence was kept blinded from the other investigators at all times. Then, after a swab test at the reference center and obtaining the patient's consent, the kits were delivered to patients by two investigators (D.G. and A.B.) who assigned participants to interventions. The kits were kept blinded to patients at all times in this clinical trial. In addition, the analysis of the data and statistical treatment was performed by an external investigator with no clinical involvement in the trial (K.F), who was unable to identify the intervention groups. Therefore, the investigators, patients, and outcomes assessor were blinded to group assignment.

\section{Interventions}


The patients were divided into two groups:

- Control group ( $\mathrm{N}=250)$ : carried out oral hygiene with mouthwash and dentifrice Non-APD.

- APD group ( $\mathrm{N}=250)$ : carried out oral hygiene with mouthwash and dentifrice containing APD.

The videos with instructions for oral hygiene were sent via WhatsApp. All participants were instructed to floss twice a day, to place the same amount of dentifrice and brush the teeth and tongue for 2 minutes minutes/three times a day, and then to gargle/rise with $5 \mathrm{ml}$ of mouthwash for 1 minute/three times a day. They were also instructed to wait 30 minutes to eat and drink after using the oral hygiene products. This oral hygiene protocol was started on the morning of the first day after swab collection and continued for 7 days. Participants did not use any other oral hygiene products during the study.

\section{Data collection}

For the analysis of clinical symptoms, a research instrument was used to collect self-reports of the episodes, in their natural environment, through an application, according to a previous study. ${ }^{25}$ Each participant previously received (at the baseline) instructions for responding to links via mobile messages via WhatsApp. The questionnaire was sent to collect the demographic characteristics of the patients, clinical data about COVID-19 (symptoms), and oral hygiene products compliance using the Mentimeter system (Mentimeter AB, Stockholm, Sweden) in three times: T0 (baseline - before using the oral hygiene products); T3 (three days after); and T7 (seven days after). All questionnaires were answered in the evening and were identified from the randomization code.

For the diagnosis of COVID-19, the samples were processed in two laboratories (Central Laboratory of Paraná State - Lacen, Curitiba, PR, Brazil, and Research Laboratory in Applied Immunology, Department of Pathology, Clinical Analysis and Toxicology, State University of Londrina, Londrina, PR, Brazil), following the same protocol. The analysis of RNA viral was performed by RT-PCR using TaqPath ${ }^{\text {TM }}$ COVID-19 multiplex Real-Time RT-PCR test for detection of three viral genes (ORF1ab, $\mathrm{N}$ and $\mathrm{S}$ genes). Cycle threshold values $\leq 37$ for two or more genes were considered positive for COVID-19.

The primary outcome regarding the effectiveness of the mouthwash and dentifrice containing APD in the COVID-19 was the comparison of patients who achieved an improvement in clinical symptoms from baseline (T0) to T7.

\section{Statistical Analysis}

Statistical Package for Social Sciences version 18.0 was used to conduct all analysis, establishing a confidence interval of $95 \%$ and a level of significance of $5 \%(P<0.05)$ for all tests.

To compare the demographic characteristics among the groups, the Mann-Whitney Test was used to compare age, BMI, and period between symptoms onset and swab collection and Chi-Square Test was used to compare the gender. Additionally, ChiSquare Test or Exact Fisher Test was used to compare the signs and symptoms' prevalence between the groups at the baseline. Moreover, Cochran's test was used to compare the signs and symptoms within the treatment groups alongside the follow-up period.

\section{Results}

Of the 741 individuals assessed for eligibility, 500 were enrolled at this study. After confirming the diagnosis of COVID-19 test by RT-PCR, 307 negative cases were lost to follow-up and 59 were excluded from analysis because they did not answer the clinical questionnaires or did not use the products as recommended. As shown by the study flowchart (Figure 1), 134 individuals were assessed and compared all symptoms during the follow-up period. Age-eligible participants were recruited at a reference center for the diagnosis of COVID-19, in Londrina - Brazil, from November 6-19, 2020.

Table 1 shows that the groups were paired regarding demographic and clinical characteristics, early pharmacological treatment use for COVID-19 and the possible occurrence of symptoms on relatives of participants enrolled at the study. Table 2 shows the symptoms observed at baseline. No statistically significant difference was found in the prevalence of symptoms 
between the groups at baseline. The most prevalent ones were fatigue, shortness of breath, hoarse voice, dysgeusia and hyposmia/anosmia with similar prevalence in both groups at baseline and those with a higher prevalence than $20 \%$ at the initial assessment were included for future analysis.

Table 1

Demographic and clinical characteristics of the study population $(n=134)$.

\begin{tabular}{|c|c|c|c|}
\hline Variables & $\begin{array}{l}\text { Control } \\
\text { Group } \\
(n=75)\end{array}$ & $\begin{array}{l}\text { APD Group } \\
(n=59)\end{array}$ & $\begin{array}{l}\mathrm{P}- \\
\text { value }\end{array}$ \\
\hline Age, years (Median \pm Interquartile range) & $34.2 \pm 20.9$ & $35.5 \pm 21.4$ & $0.47^{a}$ \\
\hline BMI (Median \pm Interquartile range) & $25.6 \pm 6.6$ & $26.7 \pm 6.3$ & $0.25^{a}$ \\
\hline \multicolumn{4}{|l|}{ Gender } \\
\hline Female, n (percentage) & $48(64.0)$ & $35(59.3)$ & $0.58^{b}$ \\
\hline Male, $\mathrm{n}$ (percentage) & $27(36.0)$ & $24(40.7)$ & \\
\hline \multicolumn{4}{|l|}{ Polypharmacy use } \\
\hline Yes, n (percentage) & $05(6.7)$ & $02(3.4)$ & $0.46^{c}$ \\
\hline No, n (percentage) & $70(93.3)$ & $57(96.6)$ & \\
\hline \multicolumn{4}{|l|}{ Early Pharmacological treatment for COVID } \\
\hline Yes, n (percentage) & $22(29.3)$ & $19(32.2)$ & $0.85^{\mathrm{b}}$ \\
\hline No, n (percentage) & $53(70.7)$ & $40(67.8)$ & \\
\hline \multicolumn{4}{|l|}{ Symptoms' presence on relatives after treatment } \\
\hline Yes, n (percentage) & $08(10.7)$ & $04(6.8)$ & $0.55^{c}$ \\
\hline No, n (percentage) & $67(89.3)$ & $55(93.2)$ & \\
\hline $\begin{array}{l}\text { Period between symptoms onset and swab collection, days (Median } \pm \\
\text { Interquartile range) }\end{array}$ & $4 \pm 3$ & $4.5 \pm 2$ & $0.33^{\mathrm{a}}$ \\
\hline (a) Mann-Whitney test; (b) Chi-Square test; (c) Exact Fisher test; BMI: bo & index. & & \\
\hline
\end{tabular}


Table 2

- Symptoms observed at baseline.

\begin{tabular}{|c|c|c|c|c|c|}
\hline Symptoms & $\begin{array}{l}\text { Control Grou } \\
(n=75)\end{array}$ & & $\begin{array}{l}\text { APD Group } \\
(n=59)\end{array}$ & & P-value \\
\hline & Yes & No & Yes & No & \\
\hline Cough & $20(26.7 \%)$ & $55(73.3 \%)$ & $21(35.6 \%)$ & $38(64.4 \%)$ & 0.27 \\
\hline Fatigue & $46(61.3 \%)$ & $29(38.7 \%)$ & $32(54.2 \%)$ & $27(45.8 \%)$ & 0.69 \\
\hline Shortness of breath & $40(53.3 \%)$ & $35(46.7 \%)$ & $32(54.3 \%)$ & $27(45.8 \%)$ & 0.43 \\
\hline Hyposmia/ Anosmia & $33(44.0 \%)$ & $42(56.0 \%)$ & $31(52.5 \%)$ & $28(47.5 \%)$ & 0.33 \\
\hline Dysgeusia & $34(45.3 \%)$ & $41(54.7 \%)$ & $30(50.8 \%)$ & $29(49.2 \%)$ & 0.66 \\
\hline Hoarse voice & $41(54.7 \%)$ & $34(45.3 \%)$ & $34(57.6 \%)$ & $25(42.4 \%)$ & 0.73 \\
\hline Sore throat & $29(38.7 \%)$ & $46(61.3 \%)$ & $18(30.5 \%)$ & $41(69.5 \%)$ & 0.33 \\
\hline Nasal congestion & $24(32.0 \%)$ & $51(68.0 \%)$ & $17(28.8 \%)$ & $42(71.2 \%)$ & 0.69 \\
\hline Chest pain & $18(24.0 \%)$ & $57(76.0 \%)$ & $17(28.8 \%)$ & $42(71.2 \%)$ & 0.53 \\
\hline Diarrhea & $16(21.3 \%)$ & $59(78.7 \%)$ & $13(22.0 \%)$ & $46(78.0 \%)$ & 0.92 \\
\hline Irritability / confusion & $22(29.3 \%)$ & $53(70.7 \%)$ & $17(28.8 \%)$ & $42(71.2 \%)$ & 0.95 \\
\hline
\end{tabular}

Additionally, Tables 3 and 4 show the major symptom variation after the intervention with Control Group or APD Group, respectively. A reduction in some symptoms was observed in the Control Group (fatigue, shortness of breath, hoarse voice, sore throat, nasal congestion, and chest pain). However, on the other hand, a marked reduction in all major symptoms was observed with APD Group intervention, according to Cochran's test. No side effects of using oral hygiene products were reported in this study. 
Table 3

- Major symptoms' prevalence during the follow-up period at the Control Group.

\begin{tabular}{|c|c|c|c|c|c|c|c|}
\hline Symptoms observed & $\begin{array}{l}\text { T0 } \\
(n=75)\end{array}$ & & $\begin{array}{l}\text { T3 } \\
\left(n=74^{*}\right)\end{array}$ & & $\begin{array}{l}\text { T7 } \\
\left(n=65^{\star \star}\right)\end{array}$ & & P-value \\
\hline & Yes & No & Yes & No & Yes & No & \\
\hline Cough & $20(26.7 \%)$ & $55(73.3 \%)$ & $\begin{array}{l}12 \\
(16.2 \%)\end{array}$ & $\begin{array}{l}62 \\
(83.8 \%)\end{array}$ & $\begin{array}{l}12 \\
(18.5 \%)\end{array}$ & $\begin{array}{l}53 \\
(81.5 \%)\end{array}$ & 0.26 \\
\hline Fatigue & $46(61.3 \%)$ & $29(38.7 \%)$ & $34(45.9 \%)$ & $\begin{array}{l}40 \\
(54.1 \%)\end{array}$ & $21(32.3 \%)$ & $44(67.7 \%)$ & 0.001 \\
\hline Shortness of breath & $40(53.3 \%)$ & $35(46.7 \%)$ & $\begin{array}{l}31 \\
(41.9 \%)\end{array}$ & $\begin{array}{l}43 \\
(58.1 \%)\end{array}$ & $\begin{array}{l}24 \\
(36.9 \%)\end{array}$ & $\begin{array}{l}41 \\
(63.1 \%)\end{array}$ & 0.03 \\
\hline Hyposmia/ Anosmia & $33(44.0 \%)$ & $42(56.0 \%)$ & $\begin{array}{l}38 \\
(51.4 \%)\end{array}$ & $\begin{array}{l}36 \\
(48.6 \%)\end{array}$ & $\begin{array}{l}34 \\
(52.3 \%)\end{array}$ & 31 (47.7\%) & 0.18 \\
\hline Dysgeusia & $34(45.3 \%)$ & $41(54.7 \%)$ & $36(48.6 \%)$ & $\begin{array}{l}38 \\
(51.4 \%)\end{array}$ & $\begin{array}{l}28 \\
(43.1 \%)\end{array}$ & 37 (56.9\%) & 0.35 \\
\hline Hoarse voice & $41(54.7 \%)$ & $34(45.3 \%)$ & $\begin{array}{l}35 \\
(47.3 \%)\end{array}$ & $\begin{array}{l}39 \\
(52.7 \%)\end{array}$ & $\begin{array}{l}20 \\
(30.8 \%)\end{array}$ & $45(69.2 \%)$ & 0.004 \\
\hline Sore throat & $29(38.7 \%)$ & $46(61.3 \%)$ & $\begin{array}{l}21 \\
28.4 \%)\end{array}$ & $\begin{array}{l}53 \\
(71.6 \%)\end{array}$ & $07(10.8 \%)$ & $58(89.2 \%)$ & 0.0001 \\
\hline Nasal congestion & $24(32.0 \%)$ & $51(68.0 \%)$ & $19(25.7 \%)$ & $\begin{array}{l}55 \\
(74.3 \%)\end{array}$ & $\begin{array}{l}09 \\
(13.8 \%)\end{array}$ & $56(86.2 \%)$ & 0.008 \\
\hline Chest pain & $18(24.0 \%)$ & $57(76.0 \%)$ & $11(14.9 \%)$ & $\begin{array}{l}63 \\
(85.1 \%)\end{array}$ & $06(9.2 \%)$ & $59(90.8 \%)$ & 0.03 \\
\hline Diarrhea & $16(21.3 \%)$ & $59(78.7 \%)$ & $\begin{array}{l}14 \\
(18.9 \%)\end{array}$ & $\begin{array}{l}60 \\
(81.1 \%)\end{array}$ & $09(13.8 \%)$ & $56(86.2 \%)$ & 0.40 \\
\hline Irritability / confusion & $22(29.3 \%)$ & $53(70.7 \%)$ & $22(29.7 \%)$ & $\begin{array}{l}52 \\
(70.3 \%)\end{array}$ & $14(21.5 \%)$ & $51(78.5 \%)$ & 0.09 \\
\hline
\end{tabular}

Data are shown as the $n$ and percentage; $P$ : Cochran's test; Statistical significance set at $P<0.05$; * One patient did not answer the questionnaire; ** Ten patients did not answer the questionnaire. 
Table 4

- Major symptoms' prevalence during the follow-up period at the APD Group.

\begin{tabular}{|c|c|c|c|c|c|c|c|}
\hline Symptoms observed & $\begin{array}{l}\text { T0 } \\
(n=59)\end{array}$ & & $\begin{array}{l}\text { T3 } \\
\left(n=57^{*}\right)\end{array}$ & & $\begin{array}{l}\text { T7 } \\
(n=51 * \star)\end{array}$ & & P-value \\
\hline & Yes & No & Yes & No & Yes & No & \\
\hline Cough & $21(35.6 \%)$ & $38(64.4 \%)$ & $16(28.1 \%)$ & $\begin{array}{l}41 \\
(71.9 \%)\end{array}$ & $06(11.8 \%)$ & $45(88.2 \%)$ & 0.01 \\
\hline Fatigue & $32(54.2 \%)$ & $27(45.8 \%)$ & $22(38.6 \%)$ & $\begin{array}{l}35 \\
(61.4 \%)\end{array}$ & $11(21.6 \%)$ & $\begin{array}{l}40 \\
(78.4 \%)\end{array}$ & 0.001 \\
\hline Shortness of breath & $32(54.3 \%)$ & $27(45.8 \%)$ & $\begin{array}{l}16 \\
(28.1 \%)\end{array}$ & $\begin{array}{l}41 \\
(71.9 \%)\end{array}$ & $10(19.6 \%)$ & $41(80.4 \%)$ & 0.001 \\
\hline Hyposmia/ Anosmia & $31(52.5 \%)$ & $28(47.5 \%)$ & $26(45.6 \%)$ & $\begin{array}{l}31 \\
(54.4 \%)\end{array}$ & $17(33.3 \%)$ & $34(66.7 \%)$ & 0.03 \\
\hline Dysgeusia & $30(50.8 \%)$ & $29(49.2 \%)$ & $\begin{array}{l}18 \\
(31.6 \%)\end{array}$ & $\begin{array}{l}39 \\
(68.4 \%)\end{array}$ & $12(23.5 \%)$ & 39 (76.5\%) & 0.005 \\
\hline Hoarse voice & $34(57.6 \%)$ & $25(42.4 \%)$ & $\begin{array}{l}18 \\
(31.6 \%)\end{array}$ & $\begin{array}{l}39 \\
(68.4 \%)\end{array}$ & $07(13.7 \%)$ & $44(86.3 \%)$ & 0.001 \\
\hline Sore throat & $18(30.5 \%)$ & $41(69.5 \%)$ & $\begin{array}{l}08 \\
(14.0 \%)\end{array}$ & $\begin{array}{l}49 \\
(86.0 \%)\end{array}$ & - & $51(100.0 \%)$ & 0.0001 \\
\hline Nasal congestion & $17(28.8 \%)$ & $42(71.2 \%)$ & $09(15.8 \%)$ & $\begin{array}{l}48 \\
(84.2 \%)\end{array}$ & 03 (5.9\%) & $48(94.1 \%)$ & 0.005 \\
\hline Chest pain & $14(23.7 \%)$ & $45(76.3 \%)$ & $05(8.8 \%)$ & $\begin{array}{l}52 \\
(91.2 \%)\end{array}$ & $06(11.8 \%)$ & $45(88.2 \%)$ & 0.002 \\
\hline Diarrhea & $13(22.0 \%)$ & $46(78.0 \%)$ & $05(8.8 \%)$ & $\begin{array}{l}52 \\
(91.2 \%)\end{array}$ & - & $51(100.0 \%)$ & 0.002 \\
\hline Irritability / confusion & $17(28.8 \%)$ & $42(71.2 \%)$ & $06(10.5 \%)$ & $51(89.5 \%)$ & $04(7.8 \%)$ & $\begin{array}{l}47 \\
(92.2 \%)\end{array}$ & 0.02 \\
\hline
\end{tabular}

Data are shown as the $n$ and percentage; $P$ : Cochran's test; Statistical significance set at $\mathrm{P}<0.05$; * Two patients did not answer the questionnaire; ** Eight patients did not answer the questionnaire.

When comparing the symptoms' prevalence within the groups, dysgeusia, sore throat, irritability / confusion was less prevalent at the APD Group at T3 (Chi-Square Test, Table 5). 
Table 5

- Comparison of the symptoms' prevalence among the groups at T3 day of follow-up.

\begin{tabular}{|c|c|c|c|c|c|}
\hline \multirow[t]{2}{*}{ Symptoms observed } & \multicolumn{2}{|c|}{$\begin{array}{l}\text { Control Group } \\
(n=74)\end{array}$} & \multicolumn{2}{|l|}{$\begin{array}{l}\text { APD Group } \\
(n=57)\end{array}$} & \multirow[t]{2}{*}{ P-value } \\
\hline & Yes & No & Yes & No & \\
\hline \multirow[t]{2}{*}{ Cough } & 12 & 62 & $16(28.1 \%)$ & 41 & 0.48 \\
\hline & $(16.2 \%)$ & $(83.8 \%)$ & & $(71.9 \%)$ & \\
\hline \multirow[t]{2}{*}{ Fatigue } & $34(45.9 \%)$ & 40 & $22(38.6 \%)$ & 35 & 0.40 \\
\hline & & $(54.1 \%)$ & & $(61.4 \%)$ & \\
\hline \multirow[t]{2}{*}{ Shortness of breath } & 31 & 43 & 16 & 41 & 0.10 \\
\hline & $(41.9 \%)$ & $(58.1 \%)$ & $(28.1 \%)$ & $(71.9 \%)$ & \\
\hline \multirow[t]{2}{*}{ Hyposmia/ Anosmia } & 38 & 36 & $26(45.6 \%)$ & 31 & 0.51 \\
\hline & $(51.4 \%)$ & $(48.6 \%)$ & & $(54.4 \%)$ & \\
\hline \multirow[t]{2}{*}{ Dysgeusia } & $36(48.6 \%)$ & 38 & 18 & 39 & 0.04 \\
\hline & & $(51.4 \%)$ & $(31.6 \%)$ & $(68.4 \%)$ & \\
\hline \multirow[t]{2}{*}{ Hoarse voice } & 35 & 39 & 18 & 39 & 0.07 \\
\hline & $(47.3 \%)$ & $52.7 \%)$ & $(31.6 \%)$ & $(68.4 \%)$ & \\
\hline \multirow[t]{2}{*}{ Sore throat } & 21 & $53(71.6 \%)$ & 08 & 49 & 0.04 \\
\hline & $28.4 \%)$ & & $(14.0 \%)$ & $(86.0 \%)$ & \\
\hline \multirow[t]{2}{*}{ Nasal congestion } & $19(25.7 \%)$ & $55(74.3 \%)$ & 09 (15.8\%) & 48 & 0.17 \\
\hline & & & & $(84.2 \%)$ & \\
\hline \multirow[t]{2}{*}{ Chest pain } & $11(14.9 \%)$ & $63(85.1 \%)$ & $05(8.8 \%)$ & 52 & 0.29 \\
\hline & & & & $(91.2 \%)$ & \\
\hline \multirow[t]{2}{*}{ Diarrhea } & 14 & 60 & $05(8.8 \%)$ & 52 & 0.10 \\
\hline & $(18.9 \%)$ & $(81.1 \%)$ & & $(91.2 \%)$ & \\
\hline \multirow[t]{2}{*}{ Irritability / confusion } & 22 & $52(70.3 \%)$ & $06(10.5 \%)$ & $51(89.5 \%)$ & 0.008 \\
\hline & $(29.7 \%)$ & & & & \\
\hline
\end{tabular}

Additionally, at T7 day follow-up, shortness of breath, hyposmia/anosmia, dysgeusia, hoarse voice, sore throat, diarrhea, and irritability/confusion were more prevalent in the Control group (Chi-Square Test, Table 6). 
Table 6

- Comparison of the symptoms' prevalence among the groups at T7 of follow-up.

\begin{tabular}{|c|c|c|c|c|c|}
\hline \multirow[t]{2}{*}{ Symptoms observed } & \multicolumn{2}{|c|}{$\begin{array}{l}\text { Control Group } \\
(n=65)\end{array}$} & \multicolumn{2}{|l|}{$\begin{array}{l}\text { APD Group } \\
(n=51)\end{array}$} & \multirow[t]{2}{*}{ P-value } \\
\hline & Yes & No & Yes & No & \\
\hline \multirow[t]{2}{*}{ Cough } & 12 & 53 & $06(11.8 \%)$ & $45(88.2 \%)$ & 0.32 \\
\hline & $(18.5 \%)$ & $(81.5 \%)$ & & & \\
\hline \multirow[t]{2}{*}{ Fatigue } & $21(32.3 \%)$ & $44(67.7 \%)$ & $11(21.6 \%)$ & 40 & 0.20 \\
\hline & & & & $(78.4 \%)$ & \\
\hline \multirow[t]{2}{*}{ Shortness of breath } & 24 & 41 & $10(19.6 \%)$ & $41(80.4 \%)$ & 0.04 \\
\hline & $(36.9 \%)$ & $(63.1 \%)$ & & & \\
\hline \multirow[t]{2}{*}{ Hyposmia/ Anosmia } & 34 & $31(47.7 \%)$ & $17(33.3 \%)$ & $34(66.7 \%)$ & 0.04 \\
\hline & $(52.3 \%)$ & & & & \\
\hline Dysgeusia & $28(43.1 \%)$ & $37(56.9 \%)$ & $12(23.5 \%)$ & $39(76.5 \%)$ & 0.03 \\
\hline \multirow[t]{2}{*}{ Hoarse voice } & 20 & $45(69.2 \%)$ & $07(13.7 \%)$ & $44(86.3 \%)$ & 0.03 \\
\hline & $(30.8 \%)$ & & & & \\
\hline Sore throat & $07(10.8 \%)$ & $58(89.2 \%)$ & - & $51(100.0 \%)$ & 0.02 \\
\hline \multirow[t]{2}{*}{ Nasal congestion } & 09 & $56(86.2 \%)$ & 03 (5.9\%) & $48(94.1 \%)$ & 0.16 \\
\hline & $(13.8 \%)$ & & & & \\
\hline Chest pain & $06(9.2 \%)$ & $59(90.8 \%)$ & $06(11.8 \%)$ & $45(88.2 \%)$ & 0.65 \\
\hline Diarrhea & $09(13.8 \%)$ & $56(86.2 \%)$ & - & $51(100.0 \%)$ & 0.006 \\
\hline \multirow[t]{2}{*}{ Irritability / confusion } & $14(21.5 \%)$ & $51(78.5 \%)$ & $04(7.8 \%)$ & 47 & 0.04 \\
\hline & & & & $(92.2 \%)$ & \\
\hline
\end{tabular}

Table 7 shows the comparison of symptoms' prevalence during the follow-up between Control and APD groups. There were statistically significant differences with a higher symptoms' prevalence for the Control Group at T3 and T7.

Table 7

- Symptoms' prevalence during the follow-up period between the groups.

\begin{tabular}{|llll|}
\hline Group & T0 & T3 & T7 \\
\hline Control & 71 & 61 & 47 \\
& $(94.7 \%)$ & $82.4 \%$ & $72.3 \%$ \\
\hline APD & 56 & 38 & 27 \\
& $94.9 \%$ & $66.7 \%$ & $52.9 \%$ \\
\hline P-value & 0.95 & $\mathbf{0 . 0 3 7}$ & $\mathbf{0 . 0 3}$ \\
\hline Data are shown as the $\mathrm{n}$ and percentage; P: Chi-Square Test; Statistical significance set at $\mathrm{P}<0.05$. \\
\hline
\end{tabular}




\section{Discussion}

In light of the ongoing discussion on COVID-19 and oral health management, $2,4,26-28$ the overarching aim of this triple-blind randomized clinical trial was to evaluate the use of a mouthwash and a dentifrice containing APD on the reduction of clinical symptoms in COVID-19 patients. The results of this study showed reduced clinical symptoms self-reported by patients at home and collected by applying a questionnaire. ${ }^{25}$ The symptoms' prevalence were examined at baseline (T0) and 3 (T3) and 7 (T7) days after using APD in oral hygiene products and compared to the control group. These results are in accordance with clinical and laboratorial evidence built over this pandemic period regarding the beneficial effect of using APD in oral care products against COVID-19 in the studies samples. ${ }^{14-16,20-23}$

Understanding the pathophysiology of COVID-19 with the entry of SARS-CoV-2 through the upper airway, affinities for the nasal and oral mucosae and the salivary glands as reservoirs of the virus, ${ }^{2,29}$ becomes important to conduct investigations as our study. A recent study found the presence of SARS-CoV-2 in periodontal tissue and concluded that periodontal tissue can be a target for SARS-CoV-2 and contribute to the presence of the virus in saliva. ${ }^{3}$ In addition, a study aimed to investigate the impact of COVID-19 on the oral health of adults in China and an online cross-sectional survey based on a questionnaire was conducted in a total of 3352 participants. The authors concluded that the three most common oral problems amid the epidemic were gingival bleeding, bad breath and oral ulcers. ${ }^{7}$ In another study, ${ }^{30}$ the authors recommend that oral hygiene be maintained, if not improved, during COVID-19 to reduce bacterial load in the mouth and the potential risk of superinfection. The authors also stated that poor oral hygiene be considered a risk of complications, particularly in patients with comorbidity, and that bacteria in patients with severe COVID-19 are associated with the oral cavity and improved oral hygiene may play an important role in reducing the risk of complications. Thus, the habit of oral hygiene through mechanical cleaning should be implemented more rigorously associated with the chemical action against microorganisms, such as SARS-CoV-2.

In the current study, no statistically significant difference was found in the prevalence of clinical symptoms between the groups at baseline (Tables 1,2). There was a significant reduction in six symptoms self-reported in the Control Group during the follow-up period (Table 3 ) and a significant improvement $(\mathrm{P}<0.05)$ of all major COVID-19 symptoms in the APD group (Table 4). Oral hygiene protocol can reduce COVID-19 symptoms mainly after one week of treatment (Tables 5, 6, 7). Both groups present symptom reduction, however the APD group had a significant reduction during the follow-up ( 94.9 to $52.9 \%$ ). These results may be related to the mechanical, antimicrobial, anti-inflammatory and tissue regeneration actions. ${ }^{15,16,20-23}$ Moreover, according to the safety outcomes, no side effects were reported by the patients regarding the oral hygiene protocol. Thus, the use of oral hygiene as a strategy to reduce the COVID-19 symptoms should be considered.

There is in fact evidence that mechanical oral hygiene can reduce the viral load on the mouth and oropharynx, prevent upper respiratory tract infections, and reduce infectivity. 8,11,31,32 In our study, however, we believe that mechanical action was an adjunct that potentiated the action of APD in reducing the load of SARS-CoV-2, which was clinically demonstrated by the greater reduction in self-reported symptoms by patients in the APD Group. Thus, as previously reported, the use of APD in oral care products could positively contribute to the improvement of clinical symptomatology in CODIV-19 patients. ${ }^{22}$

In addition to mouth and pharyngeal symptoms, diarrhea could happen during COVID-19 infection since SARS-CoV-2 can reach and replicate in intestinal epithelia direct from the mouth. ${ }^{33}$ In this study, diarrhea was self-reported by patients in both groups at baseline (Control Group: 16, APD Group: 13), and at the end of one week (T7) none of the patients who used the oral hygiene APD protocol presented the symptom, unlike the group that did not use it (Tables 5 and 6 ). In the Control Group, of the 16 initial cases, 02 remained with diarrhea and 07 new cases appeared during the 7-day follow-up period (data not shown). Thus, based on self-related of the patients, we believe that the APD oral hygiene protocol may have directly contributed to the non-appearance of new cases of diarrhea during the evaluated period, from the reduction of the SARS-CoV2 viral load in the mouth and pharynx of the patients.

The main limitations of this study were that clinical data on COVID-19 symptomatology was collected from an electronic system at home. Despite the ease of obtaining the information considering the context of the pandemic, without face-to-face

Page 11/15 
interaction with the patients, it made it impossible for us to exclude any symptoms not exclusively associated with COVID-19. Another limitation was with compliance to certify the correct use of oral hygiene products. As it was also conducted electronically, the data from this study were entirely dependent on the fidelity of the responses by the participants. However, the significant reduction in symptoms during the follow-up period showed a promising path for the use of oral hygiene care.

The COVID-19 pandemic has presented moments of exacerbation and improvement, and currently with the arrival of new variants shows that the fight against SARS-CoV-2 should be maintained and intensified and with the results of recent studies, which show the effects of mouthwash in reducing the viral load in the saliva of infected individuals. Therefore, we understand that the strategy of using oral hygiene products containing antimicrobial agents becomes an important adjuvant against SARS-CoV-2.

\section{Conclusion}

Based on methodology, the results demonstrated that the regular use of mouthwash and dentifrice containing APD had a positive impact on the clinical symptoms reported by COVID-19 patients.

\section{Declarations}

\section{ACKNOWLEDGEMENT}

The authors would like to gratefully acknowledge the Londrina Municipal Health Authority for the support in the study.

Funding: This research was funded primarily by TRIALS - Oral Health \& Technologies and Golden Technology Corp. Funders contributed to the scope and design of this study; however, they did not influence the collation, management, analysis, and interpretation of the data; preparation, review, or approval of the manuscript; or the decision to submit the manuscript for publication.

The authors declare no competing interests.

\section{References}

1. Aida J, Fukai K, Watt RG. Global Neglect of Dental Coverage in Universal Health Coverage Systems and Japan's Broad Coverage. International Dental Journal. 2021. DOI: https://doi.org/10.1016/j.identj.2020.12.027

2. Huang N, Pérez P, Kato T, et al. SARS-CoV-2 infection of the oral cavity and saliva. Nature medicine. 2021;27(5):892-903.

3. Matuck BF, Dolhnikoff M, Maia GVA, et al. Periodontal tissues are targets for Sars-Cov-2: a post-mortem study. Journal of oral microbiology. 2020;13(1):1848135-1848135. DOI: 10.1080/20002297.2020.1848135

4. Matuck BF, Dolhnikoff M, Duarte-Neto AN, et al. Salivary glands are a target for SARS-CoV-2: a source for saliva contamination. The Journal of Pathology. 2021.

5. Pepsodent W. Bangladesh research summary report 2021: attitudes, behaviours and experiences of oral health during the covid-19 pandemic. Fact Sheet - Bangladesh. Campaign: \#BrushWithMe Web site.

https://www.pepsodent.com/content/dam/unilever/smile/global/digital_and_online/smile_fact_sheet_bangladesh_final38049334.pdf. Published 2021. Accessed2021.

6. Lu M, Xuan S, Wang Z. Oral microbiota: A new view of body health. Food Science and Human Wellness. 2019;8(1):8-15.

7. Zhang S, Liu C, Zhang C, Jiang H, Tai B, Du M. Impact of COVID-19 on the oral health of adults in Wuhan and China: results of a nationwide online cross-sectional questionnaire survey. BMC Oral Health. 2021;21(1):162. DOI:

10.1186/s12903-021-01533-z

8. González-Olmo MJ, Delgado-Ramos B, Ruiz-Guillén A, Romero-Maroto M, Carrillo-Díaz M. Oral hygiene habits and possible transmission of COVID-19 among cohabitants. BMC Oral Health. 2020;20(1):286. DOI: 10.1186/s12903-020-

Page $12 / 15$ 
01274-5

9. Pinzan-Vercelino CR, Freitas KM, Girão VM, da Silva DO, Peloso RM, Pinzan A. Does the use of face masks during the COVID-19 pandemic impact on oral hygiene habits, oral conditions, reasons to seek dental care and esthetic concerns? $J$ Clin Exp Dent. 2021;13(4):e369-e375. DOI: 10.4317/jced.57798

10. Elzein R, Abdel-Sater F, Fakhreddine S, et al. In vivo evaluation of the virucidal efficacy of chlorhexidine and povidoneiodine mouthwashes against salivary SARS-CoV-2. A randomized-controlled clinical trial. J Evid Based Dent Pract. 2021;21(3):101584. DOI: 10.1016/j.jebdp.2021.101584

11. Schürmann M, Aljubeh M, Tiemann $C$, Sudhoff H. Mouthrinses against SARS-CoV-2: anti-inflammatory effectivity and a clinical pilot study. Eur Arch Otorhinolaryngol. 2021;278(12):5059-5067. DOI: 10.1007/s00405-021-06873-8

12. Moosavi MS, Aminishakib P, Ansari M. Antiviral mouthwashes: possible benefit for COVID-19 with evidence-based approach. J Oral Microbiol. 2020;12(1):1794363. DOI: 10.1080/20002297.2020.1794363

13. Moreno MVM, Obrador AM, Márquez VA, García MDF. Oral antiseptics against coronavirus: in vitro and clinical evidence. Journal of Hospital Infection. 2021.

14. Poleti ML, Gregório D, Bistaffa AGI, et al. Toothbrushing with a dentifrice containing antimicrobial phthalocyanine derivative for the intraoral reduction of viral load of SARS-CoV-2: a pilot study. 2021. [Preprint] Research Square. DOI:10.21203/rs.3.rs-690819/v1.

15. Santos C, da Fonseca Orcina B, Brito Reia VC, et al.. Virucidal Activity of the Antiseptic Mouthwash and Dental Gel Containing Anionic Phthalocyanine Derivative: In vitro Study. Clin Cosmet Investig Dent. 2021 Jun 28;13:269-274. doi: 10.2147/CCIDE.S315419.

16. Santos P, Orcina B, Alves L, Oliveira R, Zangrando M, Vilhena F. A Recommendation of PHTALOX® Mouthwash for Preventing Infection and Progression of COVID-19. Acta Scient Dent Sci. 2020;4:12.

17. Schürmann M, Aljubeh M, Tiemann C, Sudhoff H. Mouthrinses against SARS-CoV-2: anti-inflammatory effectivity and a clinical pilot study. European Archives of Oto-Rhino-Laryngology. 2021:1-9.

18. Zanatta FB, Antoniazzi RP, Rösing CK. Staining and calculus formation after $0.12 \%$ chlorhexidine rinses in plaque-free and plaque covered surfaces: a randomized trial. J Appl Oral Sci. 2010;18(5):515-521. DOI: 10.1590/s167877572010000500015

19. Santos CA, Vilhena FV, Zangrando MSR. Adjuvant use of phthalocyanine derivative for calculus control. Int J Case Rep Images. 2021;12:101220Z101201CS102021.

20. Vilhena FV, Brito Reia VC, da Fonseca Orcina B, et al. The use of antiviral Phthalocyanine mouthwash as a preventive measure against COVID-19. GMS Hyg Infect Control. 2021;16. DOI: 10.3205/dgkh000395

21. da Silva Santos PS, da Fonseca Orcina B, Machado RRG, et al. Beneficial effects of a mouthwash containing an antiviral phthalocyanine derivative on the length of hospital stay for COVID-19: randomised trial. Sci Rep. 2021;11(1):19937. DOI: 10.1038/s41598-021-99013-5

22. Orcina BdF, Vilhena FV, Oliveira RC, et al. A Phthalocyanine Derivate Mouthwash to Gargling/Rinsing as an Option to Reduce Clinical Symptoms of COVID-19: Case Series. Clinical, Cosmetic and Investigational Dentistry. 2021;13:47.

23. Orcina BdF, Santos PSdS. Oral Manifestation COVID-19 and the Rapid Resolution of Symptoms Post-Phtalox Treatment: a Case Series. Int J Odontostomat. 2021;15(1):67-70.

24. Moher D, Hopewell S, Schulz KF, et al. CONSORT 2010 explanation and elaboration: updated guidelines for reporting parallel group randomised trials. International journal of surgery. 2012;10(1):28-55.

25. Menni C, Valdes AM, Freidin MB, et al. Real-time tracking of self-reported symptoms to predict potential COVID-19. Nature medicine. 2020;26(7):1037-1040.

26. Imai K, Tanaka H. SARS-CoV-2 Infection and Significance of Oral Health Management in the Era of "the New Normal with COVID-19". International Journal of Molecular Sciences. 2021;22(12):6527. 
27. Iranmanesh B, Khalili M, Amiri R, Zartab H, Aflatoonian M. Oral manifestations of COVID-19 disease: A review article. Dermatologic therapy. 2021;34(1):e14578.

28. Kamel AHM, Basuoni A, Salem ZA, AbuBakr N. The impact of oral health status on COVID-19 severity, recovery period and C-reactive protein values. British dental journal. 2021:1-7.

29. Jafer MA, Hazazi MA, Mashi MH, et al. COVID-19 and Periodontitis: A Reality to Live with. The Journal of Contemporary Dental Practice. 2020;21(12):1399.

30. Sampson V, Kamona N, Sampson A. Could there be a link between oral hygiene and the severity of SARS-CoV-2 infections? Br Dent J. 2020;228(12):971-975. DOI: 10.1038/s41415-020-1747-8

31. Satomura K, Kitamura T, Kawamura T, et al. Prevention of upper respiratory tract infections by gargling: a randomized trial. Am J Prev Med. 2005;29(4):302-307. DOI: 10.1016/j.amepre.2005.06.013

32. Nagatake T, Ahmed K, Oishi K. Prevention of respiratory infections by povidone-iodine gargle. Dermatology. 2002;204 Suppl 1:32-36. DOI: 10.1159/000057722

33. D'Amico F, Baumgart DC, Danese S, Peyrin-Biroulet L. Diarrhea during COVID-19 infection: pathogenesis, epidemiology, prevention, and management. Clinical Gastroenterology and hepatology. 2020;18(8):1663-1672.

\section{Figures}




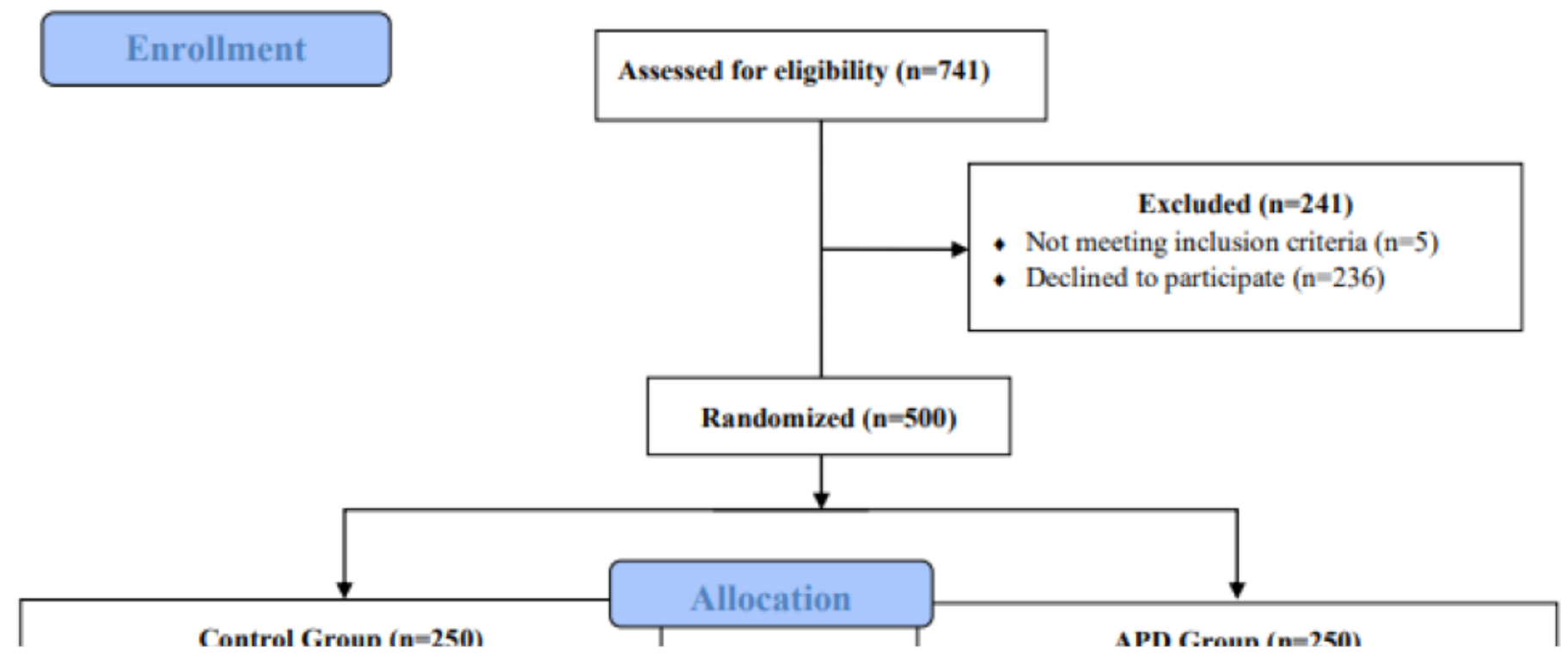

Figure 1

CONSORT flow diagram. 